\title{
POTENSI BUBUR ASE SEBAGAI DAYA TARIK WISATA KULINER JAKARTA
}

\author{
Lila Muliani ${ }^{\mathrm{a}, 1, *}$ \\ ${ }^{\mathrm{a}}$ Hospitaliti dan Pariwisata, Institut Stiami, Jakarta \\ ${ }^{1}$ Email :lilamuliani@gmail.com* \\ * corresponding author
}

\section{ARTICLE INFO}

\section{Keywords}

Potensi ,Dayatarik

Wisata, Kuliner Jakarta,

Bubur Ace

\begin{abstract}
Food and tourism can not be separated. Travellers will always need food to fill his stomach. However, trend of culinary tourism which begun to be popular in the beginning of the year 2000 has come to the definition that food is not only something to satisfy someones' hunger. Traditional food of one destination could become an attraction to motivate tourists to come.

Jakarta as the capital city that never stop welcoming tourists - domestic and abroad - to come, has many potential culinary attractions. Unfortunately, until today, traditinal food of Betawi - Jakarta people - that is known by people are very limited in number. The delightfull of Betawi cuisine is not yet being tourist attractions.

This study was conducted to analyze Bubur Ase, one of Betawi cuisine, to become a culinary attractions for tourist to come. This special dish is very unique since it is a mixture of porridge, beef stew in sweet soy sauce, and vegetable pickles. The taste is different from another porridge that is already famous.

This qualitative research uses primary data from observations, FGD, and in depth interview with Betawi culinary experts. SWOT analysis is used to get a whole picture of internal and external factors that is affected Bubur Ase. The resulf of the study shows that Bubur Ase is potential to become an attractiom for culinaru tourism in Jakarta. The uniqueness and harmonization of taste, historical stories, cultural values and philosophies in a bowl of Bubur Ase are the strenghts that can be developed and promoted. Some weaknesses and threats could be overcome if this dish is already popular.
\end{abstract}

\begin{abstract}
ABSTRAK
Makanan dan pariwisata merupakan dua hal yang tak terpisahkan. Kemana pun seseorang berwisata, tentu akan selalu membutuhkan makanan untuk mengisi perutnya. Namun, tren wisata kuliner yang berkembang sejak awal tahun 2000 lalu, memposisikan makanan bukan hanya sekedar pengganjal rasa lapar. Makanan tradisional yang menjadi kekhasan sebuah daerah bisa menjadi daya tarik yang menimbulkan motivasi berkunjung bagi wisatawan.

Jakarta, sebagai ibukota yang tak pernah sepi dari kunjungan wisatawan, baik dalam ataupun luar negeri, memiliki banyak potensi kekayanan kuliner yang dapat menjadi daya tarik wisata. Sayangnya hingga saat ini jumlah makanan tradisional Betawi yang dikenal masyarakat masih terbatas. Kelezatan kuliner Betawi pun tampaknya belum cukup kuat menjadi faktor daya tarik yang memotivasi wisawatan untuk datang.

Penelitian ini dilakukan untuk menganalisa potensi salah satu makanan tradisional Betawi, yaitu Bubur Ase, untuk dapat menjadi daya tarik wisata kuliner di Jakarta. Sajian Bubur Ase ini unik karena merupakan perpaduan bubur, semur, dan asinan. Cita rasanya berbeda dari bubur lain yang sudah terkenal.

Penelitian kualitatif ini menggunakan data primer dari hasil observasi, FGD dan in depth interview dengan tokoh dan pakar kuliner Betawi, serta data sekunder dari berbagai buku dan informasi digital. Analisis dilakukan dengan menggunakan SWOT analysis untuk medapatkan gambaran faktor internal dan eksternal yang mempengaruhi Bubur Ase.
\end{abstract}


Hasil penelitian menyatakan bahwa Bubur Ase memiliki potensi sebagai daya tarik wisata kuliner Jakarta. Keunikan dan harmonisasi cita rasa, cerita sejarah, nilai budaya dan filosofi yang tersimpan dalam semangkuk Bubur Ase merupakan kekuatan yang dapat dikembangkan dan dipromosikan. Kekurangan dan ancaman yang ada dapat teratasi jika Bubur Ase sudah dapat menjadi daya tarik bagi wisatawan.

\section{PENDAHULUAN}

Kekayaan kuliner tradisional suatu daerah merupakan salah satu daya tarik bagi wisatawan. Tak bisa dipungkiri, kini tak sedikit wisatawan yang sengaja datang ke sebuah destinasi demi mendapatkan pengalaman mencicipi kelezatan makanan hingga melihat langsung prosesi pembuatannya yang autentik.

Makanan dan budaya tidak bisa dipisahkan. Ketertarikan wisatawan terhadap kekayaan budaya menjadi alasan kuat yang mendorong berkembangnya tren culinary tourism yang didasari oleh adanya konsep cultural food. Menurut Long (1998), culinary tourism merupakan bentuk eksplorasi wisatawan terhadap cita rasa makanan dan kebiasaan makan daerah tertentu. Oleh karena itu, makanan tradisional menjadi salah satu poin penting yang wajib dikemas sebaik mungkin.

Meski masih tergolong niche market, wisata kuliner yang berkembang kini bukan sekedar berwisata sambil makan apa adanya, sekedar kenyang. Wisatawan ingin dapat memahami tentang apa, siapa, mengapa, dan bagaimana kebudayaan suatu daerah juga terlukis lewat makanan tradisionalnya. Adanya konsep culinary tourism ini telah membuat makanan tradisional menjadi salah satu daya tarik wisata.

Melihat tren tersebut, sebagai negara yang kaya akan ragam budaya, sudah sepatutnya kita mengembangkan aspek wisata ini. Lebih dari 900 etnis yang tersebar di 17.000-an pulau merupakan modal besar yang siap untuk dikembangkan. Potensi wisata kuliner di Indonesia jelas tak perlu diragukan.

Jakarta, sebagai ibukota, tentunya menjadi salah satu destinasi wisata yang banyak diminati wisatawan. Bill Clinten (2018) menuliskan bahwa dari 10 kota di Indonesia yang paling banyak dicari di Google, Jakarta menduduki peringkat nomor satu. Adanya berbagai pilihan pusat perbelanjaan membuat kota ini menjadi salah satu destinasi wisata belanja yang menggiurkan.

Aneka pilihan tempat makan, dari mulai kelas kaki lima hingga bintang lima, di Jakarta pun banyak menjadi target wisatawan. Sayangnya, di antara beragam pilihan makanan yang ditawarkan di Jakarta, jenis makanan tradisional Jakarta - makanan khas Betawi - belum terlalu banyak tersedia. Kalaupun ada, variasi makanan yang ditawarkan masih sangat terbatas dan bahkan jumlah restoran atau rumah makan yang menyajikannya masih jauh lebih sedikit dibandingkan jenis makanan fast food.

Padahal kekayaan kuliner khas Betawi tak kalah lezat dan menggiurkan. Ada cukup banyak pilihan makanan Betawi yang berpotensi untuk dipromosikan sebagai daya tarik wisata. Salah satunya adalah Bubur Ase. Meski ada begitu banyak jenis bubur di Indonesia, sajian Bubur Ase ini memiliki keunikan yang tak ditemukan dalam sajian bubur lain. Citarasanya komplet, kandungan gizinya cukup tinggi, nilai sejarah dan filosofinya pun menarik.

Tetapi, kini sudah tak mudah untuk mendapatkan Bubur Ase di Jakarta. Makanan ini menjadi langka bukan karena bahan-bahannya sudah sulit didapat, tetapi karena permintaannya sudah tidak banyak lagi. Sebagaimana teori supply-demand, jika permintaan menurun maka lama kelamaan ketersediaannya pun akan berkurang dan bahkan bisa habis. Harus diakui, makanan tradisional kini banyak yang sudah sulit ditemukan di pasaran. Generasi muda, khususnya, lebih terbiasa menyantap makanan siap saji (fast food).

Demi melestarikan Bubur Ase sebagai kuliner khas Betawi yang menjadi salah satu modal penting dalam culinary tourism, penulis melakukan penelitian untuk mengkaji potensi Bubur Ase sebagai daya tarik wisata di Jakarta, dengan rumusan sebagai berikut:

1. Melakukan studi mendalam untuk mengidentikasi Bubur Ase dari sudut pandang sejarah/asal usul, budaya, dan filosofi.

2. Melakukan analisis SWOT untuk mengetahui potensi Bubur Ase sebagai daya tarik wisata kuliner di Jakarta.

\section{TINJAUAN PUSTAKA}

\section{Definisi Wisata Kuliner}

Tren wisata kuliner (culinary tourism) relatif baru dalam dunia pariwisata. Istilah wisata kuliner sendiri pertama kali dimunculkan oleh seorang asisten Profesor Food and Culture dari Bowling Green State University, Ohio, bernama Lucy Long pada tahun 1998. Menurutnya, culinary toursim didefinisikan sebagai eksplorasi wisatawan terhadap cita rasa makanan dan kebiasaan makan daerah tertentu. 
Selanjutnya, Eric Wolf semakin mempopulerkan culinary toursim dengan mendirikan The International Culinary Tourism Association di tahun 2003. Menurut Wolf, definisi culinary toursim atau wisata kuliner adalah tentang makanan, menjelajahi dan menemukan budaya dan sejarah melalui makanan dan kegiatan terkait makanan dalam menciptakan pengalaman yang mengesankan.

Istilah culinary tourism pun kian populer. Dengan semangat untuk semakin mengembangkan aspek kuliner dalam pariwisata, bermunculanlah beragam definisi dan interpretasi tentang culinary tourism yang dilakukan lewat berbagai studi dan kajian.

Culinary tourism includes any tourism experience in which one learns about, appreciates, and/or consumes food and drink that reflects the local, regional, or national cuisine, heritage, culture, tradition, or culinary techniques (Culinary tourism in Ontario, Strategy and Action Plan, 2005-2015).

Melihat berbagai definisi di atas, sekedar menikmati makanan yang tersaji selama berwisata ke sebuah daerah tertentu tidak dapat digolongkan sebagai wisata kuliner. Dalam teori motivasi yang mengelompokkan motivasi wisatawan dalam 4 kelompok, maka seorang culinary tourist berada dalam kelompok cultural motivation (motivasi budaya), di mana seorang wisatawan datang ke suatu daerah untuk mengetahui tradisi, adat, budaya, atau kesenian dari daerah tersebut. Termasuk juga ketertarikan terhadap objek peninggalan sejarah (Al Akbar, W., 2014).

Berdasarkan motivasinya, Hall, C.M, Sharples, L., et al (2003) membagi food tourism atas tingkat ketertarikan wisatawan untuk berkunjung ke suatu destinasi wisata menjadi 3 tingkatan, yaitu:

1. Gastronomic Tourism. Wisata jenis ini dilakukan oleh wisatawan dengan motivasi sangat tinggi terhadap makanan atau minuman tertentu di wilayah tertentu. Keingian berkunjung tersebuat biasanya dihubungkan dengan harga makanan yang tinggi, kategori restoran bintang lima, perkebunan anggur, atau festival.

2. Culinary Tourism. Keinginan untuk mengunjungi festival lokal, pasar, atau perkebunan karena merupakan bagian dari destinasi wisata yang diikutinya.

3. Rural/Urban Tourism. Jenis wisata yang memandang makanan sebagai bagian dari kebutuhan hidup. Ketertarikan wisatawan buka pada makanannya, tetapi jika mereka merasakan cita rasa yang tidak enak, mereka masih tertarik untuk mencoba.

Di Indonesia, tren wisata kuliner mulai berkembang pesat sejak Bondan Winarno memandu sebuah acara tentang wisata kuliner yang tayang di salah satu stasiun tivi swasta. Tak dipungkiri, sejak itu makanan kerap menjadi objek yang sengaja dicari dan dikejar wisatawan saat berkunjung ke sebuah daerah.

\section{Daya Tarik Wisata}

Dalam UU No. 9 tahun 1990 tentang kepariwisataan disebutkan bahwa daya tarik wisata adalah sesuuatu yang menjadi sasaran wisata. Daya tarik wisata dapat dibagi menjadi 3 kelompok. Pertama, daya tarik wisata ciptaan Tuhan yang berwujud keadaan alam, flora dan fauna. Kedua, daya tarik wisata hasil karya manusia yang berwujud museum, peninggalan sejarah, seni dan budaya, wisata agro, wisata buru, wisata petualangan alam, taman rekreasi dan kompleks hiburan. Ketiga, daya tarik wisata minat khusus, seperti berburu, mendaki gunung, gua, industri dan kerajinan, tempat perbelanjaan, sungai air deras, tempat-tempat ibadah, tempat ziarah dan lain-lain.

Definisi senada tentang daya tarik wisata juga diberikan oleh Direktoral Jendral pemerintahan. Daya tarik wisata dibagi menjadi tiga macam. Pertama, daya tarik wisata alam adalah sumber daya alam yang berpotensi serta memiliki daya tarik bagi pengunjung baik dalam keadaan alami maupun setelah ada usaha budi daya. Kedua, daya tarik wisata sosial budaya dapat dimanfaatkan dan dikembangkan sebagai objek dan daya tarik wisata, meliputi museum, peninggalan sejarah, upacara adat, seni pertunjukan dan kerajinan. Ketiga, daya tarik wisata minat khusus merupakan jenis wisata yang baru dikembangkan di Indonesia. Wisata ini lebih diutamakan pada wisatawan yang mempunyai motivasi khusus.

Istilah daya tarik wisata dalam literatur luar negeri dikenal dengan istilah tourist attraction yang berarti segala sesuatu yang menjadi daya tarik bagi seseorang untuk berwisata mengunjungi suatu daerah tertentu. Secara lebih mendalam, menurut Mariotti dalam Gunardi (2010), tourist attraction terbagi menjadi dua, yaitu tourism resources dan tourist service.

Tourism resources disebut juga dengan attractive spontance, yang didefinisikan sebagai segala sesuatu yang ada di sebuah daerah wisata dan menjadi daya tarik bagi wisatawan. Misalnya adalah benda-benda yang ada alam (pemandangan, iklim, kontur tanah, atau flora dan fauna), hasil ciptaan manusia (terkait kebudayaan dan benda-benda bersejarah), dan tata cara hidup masyarakat setempat atau the way of life (kebudayaan lokal). 
Sedangkan tourist service disebut juga dengan istilah attractive device, yang meliputi semua fasilitas dan aktivitas yang pengadaannya disiapkan oleh perusahaan lain secara komersial. Meski tourist service tidak menjadi bagian langsung dari daya tarik wisata, namun kehadirannya juga cukup dibutuhkan.

\section{Bubur Ase Sebagai Makanan Tradisional Betawi}

Menurut Sastroamidjojo, S. (1995), yang dapat dikategorikan sebagai makanan makanan tradisional adalah makanan yang memiliki kiteria sebagai berikut: (1) biasa dikonsumsi sejak beberapa generasi, (2) memiliki cita rasa yang cocok dengan selera masyarakat, (3) tidak bertentangan dengan agama, keyakinan, dan kepercayaan masyarakat lokal, (4) terbuat dari bahan makanan serta bumbu-bumbu yang tersedia di sekitar lingkungan setempat.

Salah satu makanan tradisional khas Betawi yang mulai langka adalah Bubur Ase. Bahkan mungkin tak semua orang Betawi, khususnya generasi muda, tahu dan mengenal sajian yang satu ini. Mengapa demikian? Karena kini tak banyak lagi penjual Bubur Ase yang ada di wilayah Jakarta. Beberapa penjual yang cukup populer ada di daerah Kebon Kacang-Tanah Abang dan Pasar Gandaria.

Bisa dibilang Bubur Ase merupakan makanan yang dulunya dinikmati oleh sebagian besar masayarakat Betawi yang disebut sebagai Betawi Tengah. Berdasarkan ciri kebudayaannya, masyarakat Betawi dibagi menjadi Betawi Tengah (Betawi Kota) dan Betawi Pinggir (Betawi Ora). Sedangkan jika dilihat dari geografisnya, pembagiannya ditambah satu lagi, yaitu Betawi Pesisir (Purbasari, M., 2010).

Dijelaskan lebih lanjut dalam Purbasar, M (2010), yang disebut masyarakat Betawi Kota adalah masyarakat yang tinggal di wilayah Jakarta (kini seputaran Jakarta Pusat) yang dulu disebut Keresidenan Batavia. Dalam perkembangannya kemudian, secara lebih spesifik lagi wilayah Tanah Abang termasuk dalam distrik Welvreden. (Sedyawati, E., et al, 1986).

Akulturasi budaya yang terjadi di kawasan Betawi Tengah cukup banyak, mengingat kawasan ini pernah didaulat menjadi pusat pemerintahan VOC, pengganti Batavia yang kondisinya di masa itu sedang mengalami permasalahan, terutama di bidang kesehatan, akibat letusan Gunung Salak tahun 1696 dan kondisi lingkungan yang buruk.

Pada masa pemerintahan Belanda, wilayah Weltevreden ini berkembang pesat dan menjadi kawasan elit dengan tingkat modernitas yang tinggi. Hal ini membuat kebudayaan, termasuk kuliner, di wilayah Betawi Tengah memiliki ciri khas yang membedakannya dengan wilayah Betawi pinggir dan Betawi pesisir.

Sedangkan Betawi Pinggir terdiri dari dua kelompok, yaitu bagian utara, barat, dan Tangerang yang banyak dipengaruhi kebudayaan Tiongkok serta bagian timur, selatan, Bekasi, dan Bogor yang lebih banyak mendapatkan pengaruh dari kebudayaan Sunda. Pengaruh Melayu dirasakan cukup kuat pada masyarakat penduduk pesisir dan tengah, sementara pengaruh kebudayaan Sunda cukup kental pada kebudayaan penduduk pinggiran dan udik. Namun, keempat subwilayah kebudayaan itu diikat oleh satu bahasa yang sama, yaitu bahasa Melayu (Purbasari, M., 2010).

\section{METODE PENELITIAN}

Peneliltian ini merupakan penelitian yang bersifat deskriptif kualitatif. Pembahasan dilakukan dengan penjelasan deskripsi. Pendekatan kualitatif menurut Anselm Strauss dan Juliet Corbin merupakan penelitian yang menghasilkan temuan tanpa bantuan prosedur statistik dalam analisisnya.

Data yang didapat bersumber dari data primer dan sekunder. Data primer diperoleh dari narasumber melalui observasi langsung, wawancara mendalam (in depth interview) dan FGD (Focus Group Discussion). Narasumber yang menjadi informan merupakan pakar/tokoh dan ahli kuliner Betawi. Semua hasil wawancara dan observasi dicatat dengan lengkap dan teliti. Sedangkan data sekunder didapatkan dari sumber tertulis, baik buku maupun informasi digital, hingga dokumentasi lain yang berkaitan dengan obyek penelitian ini, yaitu Bubur Ase dan kuliner Betawi pada umumnya.

Narasumber untuk penelitian ini adalah Yahya Andi Saputra, Anisa Diah Sitawati, dan Hj Cucu Sulaicha yang nama dan kiprahnya dalam pelestarian kuliner Betawi sudah tak perlu lagi diragukan. Ketiganya juga aktif di Lembaga Kuliner Betawi. Wawancara mendalam yang dilakukan terhadap para narasumber ini diharapkan dapat memberi pandangan, masukan, dan saran yang komprehensif tentang potensi Bubur Ase sebagai daya tarik wisata kuliner Jakarta. 


\section{HASIL DAN PEMBAHASAN}

\section{Deskripsi dan Asal Muasal Bubur Ase}

Bubur Ase sangat berbeda dari bubur nasi lainnya.Tidak seperti Bubur Cianjur, Bubur Cirebon, atau Bubur Sukabumi yang sudah tenar sebagai alternatif menu sarapan masyarakat yang tinggal di Jakarta. Bubur Ase istimewa karena bubur nasi disantap bersama kuah ase dan asinan, ditambah dengan taburan kerupuk, kacang tanah goreng, kucai, kacang kedelai goreng, teri goreng, dan bawang merah goreng.

Menurut narasumber, $\mathrm{Hj}$. Cucu Sulaicha, ase atau kuah ase merupakan istilah dalam bahasa Betawi untuk menyebutkan semur encer. Semur Betawi yang sebenarnya adalah tidak berkuah banyak dan bumbunya pekat, berbeda dengan semur yang digunakan sebagai kuah Bubur Ase ini. Kuah Ase biasanya berisi potongan daging, kentang, dan ada juga yang menambahkan tahu atau telur, tergantung selera dan kemampuan ekonomi si pembuat. Meskipun kuah semur encer, bukan berarti citarasanya jadi kurang lezat. Penggunaan rempah khas sajian semur, seperti pala, merica, jahe, dan cengkih tetap jadi andalan.

Sumber lain ada yang mengatakan bahwa kata ase merupakan akronim dari asinan - semur. Selain kuah semur, Bubur Ase memang disantap bersama asinan sayuran. Isinya bisa bervariasi, antara lain adalah sawi asin, tauge, mentimun, lokio, hingga lobak. Kuah asinan yang asam segar berpadu harmonis dengan kuah ase yang manis gurih. Taburan ikan teri, kacang tanah dan kerupuk semakin menyempurnakan cita rasanya.

Bubur Ase sangat cocok menjadi pilihan menu sarapan meningat kombinasinya yang komplet dan padat gizi. Sajian ini dikenal juga dengan sebutan 'bubur dingin' karena saat menyantapnya, bubur nasi tidak perlu dalam kondisi panas, seperti sajian bubur lainnya. Bubur nasinya boleh tersaji dalam suhu ruang, namun kuah ase yang akan dituangkanlah yang harus panas sehingga saat bercampur bubur dan kuahnya menjadi hangat.

Bahan-bahan dan rempah untuk membuat Bubur Ase tidak ada yang unik dan langka. Semua bahan dan bumbunya mudah ditemukan di pasaran. Bahan yang sedikit unik hanyalah sawi asin untuk membuat asinan, namun bukan berarti sulit mendapatkannya. Sawi asin biasanya dijual bersama dengan tahu, bakso, dan produk frozen food lain serta bumbu-bumbu khas dapur Tionghoa, dijajakan oleh pedagang yang umumnya keturunan Tionghoa.

Meski bahannya mudah didapat, namun membuat Bubur Ase memerlukan keahlian, khususnya dalam membuat bubur. Tidak mudah membuat bubur yang tidak encer dan teksturnya halus. Diperlukan pengalaman dan trik khusus.

Untuk melengkapi kelezatan, seperti bubur nasi pada umumnya, Bubur Ase bisa disantap dengan sate. Tak hanya sate ati ampela, sate lembut atau sate asem khas Betawi yang terbuat dari daging sapi juga biasa menjadi pendamping semangkuk Bubur Ase ini.

Bubur Ase terbukti sebagai makanan tradisional Betawi karena sudah memenuhi 4 kriteria yang dipaparkan dalam Sastroamidjojo, S. (1995), yaitu: (1) biasa dikonsumsi sejak beberapa generasi, (2) memiliki cita rasa yang cocok dengan selera masyarakat, (3) tidak bertentangan dengan agama, keyakinan, dan kepercayaan masyarakat lokal, (4) terbuat dari bahan makanan serta bumbu-bumbu yang tersedia di sekitar lingkungan setempat. Penjual Bubur Ase yang ada di kawasan Tanah Abang kini sudah dipegang oleh generasi kedua, citarasanya diminati oleh masyarakat setempat, tidak mengandung bahan yang nonhalal, serta semua bahan-bahannya mudah didapat.

\section{Kajian Budaya \& Filosofi}

Banyak sumber yang menceritakan bahwa bubur nasi merupakan salah satu jenis kuliner yang dibawa oleh masyarakat Tionghoa. Konon, bubur nasi sudah ada di Tionghoa sejak 238 SM di masa kekaisaran Shih Huang Ti saat tanpa sengaja kaisar Shih Huang Ti menumpahkan sup panas ke dalam mangkuk nasinya. Hal ini membuat nasi lebih lembut, mengembang dan menjadi lebih banyak. Kejadian ini justru menjadi inspirasi bagi Kaisar untuk mengatasi kesulitan yang melanda rakyatnya akibat musim kemarau yang berkepanjangan. Kaisar akhirnya meminta juru masak untuk memasak beras yang ada menjadi bubur sehingga lebih bisa dimakan oleh lebih banyak orang.

Prof Murdijati Gardjito, peneliti dari UGM (Universitas Gajah Mada), Yogyakarta, juga menyampaikan pendapat yang sama, bahwa bubur merupakan simbol pemerataan. Artinya dengan memasak bubur, makan bisa lebih merata dan bisa tersaji untuk lebih banyak orang. Dengan menggunakan beras dalam jumlah yang sama, jika dibuat menjadi bubur, porsinya bisa mencapai 2-3 kali porsi untuk nasi.

Namun menurut narasumber Yahya Andi Saputra, budayawan Betawi, bubur dalam budaya Betawi memiliki makna tersendiri. Bukan sebagai simbol keterbatasan, justru bubur menjadi salah satu sajian yang 
memiliki makna yang skaral, sebab sering menjadi salah satu menu yang hadir dalam upacara-upacara adat. Misalnya, dalam Upacara Bebaritan/Baritan atau yang juga dikenal dengan Sedekah Bumi.

Upacara adat yang juga dilakukan dalam tradisi Jawa ini merupakan ritual tradisional yang sudah berlangsung turun temurun yang bertujuan sebagai bentuk ungkapan syukur atas panen yang melimpah dan menghormati roh halus pelindung kampung. Selain itu, bubur juga hadir dalam upacara-upacara adat lainnya, seperti saat bayi lahir dan selamatan bayi usia tujuh bulan.

Ditilik dari bahan-bahan yang digunakan, hidangan ini mencermikan kebudayan masyarakat Betawi yang multikultur. Setidaknya dalam semangkuk Bubur Ase terdapat pencampuran tiga kebudayaan, yaitu Tionghoa, Timur Tengah, dan Eropa. Karena proses akulturasi makanan bersifat timbal balik, banyak unsur makanan asing ini yang diserap penduduk lokal Betawi. Bahan makanan yang dibawa atau dikembangkan pendatang Tionghoaa yang terdapat dalam Bubur Ase adalah taoge, tahu, dan kecap. Sedangkan pengaruh Eropa terekam dalam semur yang berasal dari bahasa Belanda, Smoor.

Smoor dalam bahasa Belanda berarti masakan yang direbus dengan tomat dan bawang secara perlahan (stew). Dalam salah satu buku resep tertua dan paling lengkap mendokumentasikan resep masakan di Hindia Belanda berjudul Groot Nieuw Volledig Oost-Indisch Kookboek yang terbit pada 1902, terdapat 6 resep semur. Buku ini menegaskan bahwa smoor yang kemudian diserap menjadi semur adalah masakan yang dikembangkan di dalam dapur Indis, kaum peranakan Eropa.

Penggunaan kecap dalam semur merupakan bagian dari pengaruh Tionghoa, sedangkan penggunaan rempah-rempah dalam racikan bumbu semur merupakan pengaruh dari Timur Tengah. Perpaduan 3 budaya ini oleh masyarakat lokal diracik menjadi hidangan Semur Betawi yang sangat terkenal hingga saat ini.

\section{Potensi Bubur Ase sebagai Daya Tarik Wisata Kuliner di Jakarta}

Untuk melakukan analisa potensi Bubut Ase sebagai daya tarik wisata kuliner di Jakarta, perlu dilakukan analisis SWOT guna mendapatkan gambaran tentang kelebihan, kekurangan, tantangan, dan ancaman yang dihadapi. Rumusan analisis SWOT Bubur Ase disimpulkan dari hasil studi literatur dan hasil FGD yang sudah dilakukan bersama para narasumber. Berikut hasil analisis yang penulis rumuskan:

\section{A. Strenght}

1. Citarasanya lezat

2. Menggunakan bahan-bahan yang mudah didapat di pasaran

3. One dish meal dengan komposisi gizi yang komplet

4. Memiliki nilai filosofi yang dapat dijadikan bahan story telling bagi pada wisatawan (daya tarik wisata)

5. Merupakan aklulturasi 3 budaya berbeda

\section{B. Weakness}

1. Belum banyak dikenal, terutama untuk generasi muda

2. Bagi wisatawan, kemungkinan dirasa unik dan tak biasa karena memadukan semur dan asinan dalam satu porsi, apalagi disantap bersama bubur.

3. Penjualnya terbatas

\section{Opportunity}

1. Tingginya kunjungan wisatawan ke Jakarta

2. Semakin banyaknya wisatawan minat khusus yang tertarik pada wisata kuliner

\section{Threat}

1. Kalah populer dengan makanan asing yang instan dan cepat saji

2. Kalah saing dengan makanan Betawi lain yang sudah lebih dulu populer

Mengacu pada analisis SWOT di atas, Bubur Ase dapat dikatakan memiliki potensi untuk dikembangkan sebagai daya tarik wisata kuliner di Jakarta. Kekuatan berupa kandungan sejarah, akluturasi budaya dan nilai filosofi dalam Bubur Ase dapat menjadi sumber atraksi wisata minat khusus. Kekuatan ini dapat dikategorikan sebagai attractive spontance hasil ciptaan manusia yang menjadi salah satu tourist attranction (Mariotti dalam Gunardi, 2010).

Bubur Ase juga dapat dijadikan motivasi wisata kuliner dengan melihat potensi yang dimilikinya. Sejalan dengan teori Hall, C.M, Sharples, L., et al (2003) tentang motivasi wisatawan dalam mengujungi destinasi wisata kuliner, Bubur Ase sangat dapat dijadikan salah satu menu istimewa dalam sebuah festival 
kuliner tradisional. Perpaduan antara bubur, semur, dan asinan merupakan sebuah keunikan yang menjadi nilai tambah.

Wisatawan pun dapat diajak mellihat secara langsung pembuatan bubur yang terkesan mudah tetapi nyatanya membutuhkan trik khusus untuk menghasilkan tekstur dan kekentalan bubur yang pas, atau diajak membuat sendiri sayur sawi asin yang menjadi bagian dari bahan pembuat asinan. Sawi asin merupakan akultrasi budaya Tiongkok yang terselip dalam semangkuk Bubur Ase. Kisah akluturasi budaya inipun dapat menjadi daya tarik bagi wisatawan yang memiliki ketertarikan pada aspek budaya.

Apabila Bubur Ase dapat terus dikembangkan dan dipromosikan sebagai salah satu daya tarik wisata kuliner di Jakarta, maka beberapa kekurangan dan ancaman yang ada dapat teratasi. Semakin banyak orang yang mengenal Bubur Ase, akan semakin populer, dan akan semakin membuat wisatawan penasaran untuk mencicipinya.

\section{KESIMPULAN DAN SARAN}

Berdasarkan penelitian yang telah dilakukan mengenai Potensi Bubur Ase sebagai Daya Tarik Wisata Kuliner Jakarta, maka berikut simpulan yang didapat:

1. Bubur Ase merupakan makanan tradisional masyarakat Betawi yang lahir dari akulturasi 3 budaya, yaitu Tiongkok, Eropa, dan Timur Tengah.

2. Bubur Ase memiliki kekuatan dan kesempatan yang sangat baik untuk menjadi salah satu pilihan daya tarik wisata kuliner di Jakarta, selain kuliner lain yang sudah lebih dulu dikenal.

Meski demikian potensi ini hanya akan menjadi sebatas wacana jika tidak didukung oleh berbagai pihak terkait, termasuk Pemerintah Kota DKI Jakarta, khususnya Dinas Pariwisata dan Kebudayaan serta para penggiat pariwisata daerah yang aktif melakukan festival kuliner dan budaya. Jika potensi Bubur Ase ini dianggap mampu menjadi salah satu daya tarik wisata kuliner di Jakarta, maka segenap langkah strategis harus mulai direncakan.

\section{DAFTAR PUSTAKA}

Al Akbar, Wiwin. 2014. Studi Potensi Wisata Kuliner di Kabupaten Indramayu Provinsi Jawa Barat. Fakultas Teknik, Universitas Negeri Yogyakarta, Yogyakarta.

Clinten, Bill. 2018. 10 Kota Tujuan Wisata Terpopuler Menurut Google. Melalui: <https://tekno.kompas.com/read/2018/10/09/17320017/10-kota-tujuan-wisata-terpopuler-di-indonesiamenurut-google $>[27 / 8 / 19]$

Gunardi, Gugun. 2010. Identifikasi Potensi Kawasan Wisata Kali Pasir Kota Tangerang. Jurnal PLANESA Vol. 1 No. 1, Jurusan Teknik Planologi, Universitas Esa Unggul, Jakarta.

Hall, C.M., Sharples, L, et al. 2003. Food Tourism Around The World. Oxford: Butterworth-Heinemann.

Permana, T.S. 2011. Makanan Tradisional sebagai Daya Tarik Wisata Kuliner di Kota Medan. Fakultas Ilmu Budaya, Universitas Sumatera Utara, Medan.

Purbasari, Mita. 2010. Indahnya Betawi. Humaniora Vol. 1 No. 1. Jurusan Desain Komunikasi Visual, Universitas Bina Nusantara. Jakarta.

Sastroamidjojo, S. 1995. Makanan Tradisional, Status Gizi, dan Produktivitas Kerja. Dalam Prosiding Widyakarya Nasional Khasiat Makanan Tradisional. Jakarta: Kantor Menteri Negara Urusan Pangan. Hal 62-66

Sedyawati, E., Rahardjo, S., Johan, I.M., Ohorella, M. 1986. Proyek Inventarisasi dan Dokumentasi Sejarah Nasional, Departemen Pendidikan dan Kebudayaan. Jakarta.

\section{Narasumber wawancara:}

Yahya Andi Saputra

Hj. Cucu Sulaicha

Hj. Anisa Diah Sitawati 